\title{
Anna PIOTROWICZ
}

\section{Małgorzata WITASZEK-SAMBORSKA}

Uniwersytet Adama Mickiewicza w Poznaniu

\section{POZNAŃSKIE REGIONALNE CZASOWNIKI I FRAZEOLOGIZMY ZWIĄZANE Z CZYNNOŚCIAMI FIZJOLOGICZNYMI ORAZ STANEM FIZYCZNYM CZLOWIEKA}

Jako badaczki gwary poznańskiej od pewnego czasu przyglądamy się regionalizmom leksykalnym i frazeologicznym $\mathrm{z}$ wybranych pól tematycznych ${ }^{1}$. Pewne $z$ nich dotyczą człowieka jako istoty fizycznej, psychicznej i społecznej. Do tej pory opublikowałyśmy trzy teksty z tego zakresu: Obraz poznaniaka w świetle Słownika gwary miejskiej Poznania pod redakcjq Moniki Gruchmanowej i Bogdana Walczaka (we współautorstwie z Bogdanem Walczakiem)2, Nazwy osób (ze względu na cechy psychiczne) w polszczyźnie miejskiej Poznania ${ }^{3}$ oraz Nazwy zawodów w polszczyźnie miejskiej Poznania ${ }^{4}$ a kolejne dwa teksty, Nazwy osób (ze względu na cechy fizyczne) w polszczyźnie miejskiej Poznania i Regionalne nazwy części ciała w polszczyźnie poznańskiej czekają na druk. W artykułach tych prezentowałyśmy materiał zgromadzony w Słowniku gwary miejskiej Poz-

1 Terminu regionalizm używamy tu w szerokim znaczeniu, obejmując nim wszystkie elementy językowe dyferencjalne względem polszczyzny ogólnej, niezależnie od ich ekstensji społecznej.

2 A. Piotrowicz, M. Witaszek-Samborska, B. Walczak, Obraz poznaniaka w świetle Słownika gwary miejskiej Poznania pod redakcja M. Gruchmanowej i B. Walczaka, [w:] Miasto - przestrzeń zróżnicowana językowo, kulturowo i społecznie 2, pod red. M. Święcickiej, Bydgoszcz 2008, s. 255-279.

3 A. Piotrowicz, M. Witaszek-Samborska, Nazwy osób (ze względu na cechy psychiczne) $w$ polszczyźnie miejskiej Poznania, „Poznańskie Studia Polonistyczne. Seria Językoznawcza" XVI, 2010, s. 213-226.

4 A. Piotrowicz, M. Witaszek-Samborska, Nazwy zawodów w polszczyźnie miejskiej Poznania [w druku]. 
nania ${ }^{5}$, biorąc pod uwagę bądź to hasła słownikowe, bądź to konteksty je ilustrujące.

Ciekawy, dotąd nieopracowany krąg semantyczny stanowią czasowniki, a także zwroty i frazy nazywające czynności oraz stany fizyczne i fizjologiczne człowieka, dopełniające regionalny językowy obraz homo sapiens. Ekscerpcja haseł słownikowych należących do tego kręgu ujawniła $\mathrm{w}$ nim nieco tylko uboższy udział tej części mowy w stosunku do rzeczowników analizowanych we wcześniejszych artykułach. Nazw (rzeczowników i wyrażeń rzeczownikowych) kategoryzujących człowieka ze względu na jego wygląd i cechy fizyczne wyekscerpowałyśmy ze Słownika gwary miejskiej Poznania ponad 140, co przy blisko 180 określeniach ze względu na cechy psychiczne wskazuje na równowagę sfer fizycznej i psychicznej jako czynników konstytuujących regionalną siatkę nominatywną w polu CZŁOWIEK. Jednostek językowych o znaczeniu czynnościowym jest natomiast około 100.

Zarejestrowane w Słowniku leksemy pochodzą z różnych odmian pisanej i mówionej polszczyzny poznańskiej. Prezentowane w artykule jednostki językowe występują zatem $\mathrm{w}$ tekstach prasowych, artystycznych, paraliterackich oraz - przede wszystkim - w wypowiedziach ustnych pokoleniowo zróżnicowanych przedstawicieli wielu środowisk i zawodów.

W zgromadzonym materiale można wskazać kilka zróżnicowanych kategorii semantycznych. Są to czasowniki i związki werbalne odnoszące się do:

- dolegliwości i słabowitości: churchlać//churchać 'kaszleć (zwłaszcza o uporczywym, męczącym kaszlu)' („Anielcia - zwierzył się żonie - chebać mnie choróbsko bierze, bo mnie trzęsie, churcham, w piersiach mnie żgo")6 , ciampać 'o regularnym, pulsującym bólu: rwać' („Ciampie mie dziś w krzyżach, pewnie bydzie dyszcz!"), dostać wilka 'odczuwać dolegliwości na skutek siedzenia na czymś zimnym' („Nie siadej na tych kamiynnych schodach, bo dostaniesz wilka"), kwiendać 'kwękać, słabować' („Ona tam zawsze kwiendała, jak ino pamiętam, ale by diabła przehycła"), ma się komuś na zdech 'ktoś czuje się bardzo słabo, jest przeświadczony o bliskim końcu swego życia' (,Niedługo już pożyję, tak mi się ma na zdech”), mgleć 'mdleć' („A potem spokojnie mglała dalej”), mieć gzik

5 Słownik gwary miejskiej Poznania, pod red. M. Gruchmanowej i B. Walczaka, Warszawa - Poznań 1997; wyd. 2. z suplementem, Warszawa - Poznań 1999.

6 Wszystkie przytaczane tu cytaty pochodzą ze Słownika gwary miejskiej Poznania. 
w kolanach // gzik komuś wchodzi w kolana 'być słabym, zmęczonym; nogi się komuś uginają ze strachu, słabości lub zmęczenia' („Po trzech miesiącach $\mathrm{w}$ szpitalu miałem taki gzik w kolanach, że na nowo uczyłem się chodzić"), mieć w girach//giyrach //gierach gzik 'odczuwać słabość i drżenie nóg na skutek silnego zmęczenia lub przestrachu' (,Jak żym doleciała na Wyspiańskiygo, to już gzik w giyrach miałam"), namóc 'nadwerężyć' („Teściowa przestrzegała żone, żeby tak mocno nie wyrabiała ciasta, bo namoże sobie ręke"), pośrupać się 'przy goleniu: pozacinać się' („Coś sie tak pośrupoł, pewno miołeś tympóm żyletke?"), przebrać 'zwichnąć, nadwerężyć” („Przebrałem ręke w czasie dźwigania tych mebli”), siekło kogoś 'kogoś zmogła choroba' („,Ale tyż mie siekło. Dawno taki paskudny grypy nie miałym"), skalczyć się 'skaleczyć się' (,Jak dziecko się skalczy, to trzeba wycyckać, żeby sie nie paskudziło'), skapucieć 'zmarnieć' („Pryndzy skapuciejesz, niż sie doczekosz za tóm gilejzóm”), umgleć 'zemdleć' („Tego już wuja nie mógł pojąć, zresztą było za mocne słóńce i ónemu sie zrobiło słabo, bo byłby o licho co umgloł"), wiukać 'czkać' („Zaś szczype odetchła i przyszła do się, ale jeszcze roz po roz wiukała”), wyglądać jak trup//śmierć na urlopie 'wyglądać mizernie, źle' („Wojtas wyglóndo jak trup na urlopie, ta jegu kobiyta nic o niegu nie dbo"), zagałuszyć się 'stracić dech' (,Sama dycho jak lekomotywa pod górke, mało się nie zagałuszy i w kuńcu krzyczy”), zajechać się 'skaleczyć się' („Od samygo rana zajechałam sie $\mathrm{w}$ palec i już nic ni moge robić"), zatajać się - zataić się 1. 'na krótko tracić (stracić) oddech' („Dziecko mi wypadło z wózika i się zataiło”), 2. 'jąkać się, zająknąć się' („Pan Noskowski sie czasem zatajo, a jak zaśpiywo, to się zaro przestaje jąkać"), zażgnq̨ć się 'ukłuć się' („Nie rusz, Anuchna, tego kwiatka, bo sie zażgniesz”), zemglić 'zemdlić' (,Jak patrze na krew, to mie zawdy zemgli"), zyzolić 'zezować' (,Moja dziewczyna troche zyzoli, ale wiysz, jak ji z tym do twarzy?");

- niesprawności ruchowej: przekipnqć się 'zbytnio się przechylić” („Przekipnół sie bez barierke i się łobalił"), przekopyrtnqú się 'przewrócić się, przekoziołkować' („Przekopyrtnął sie z góry na dół, tak było stromo”), rechlać się // rachlać się 'gramolić się, niezgrabnie się poruszać' (,- By sobie pod piecem na ryczce usiadł, kuchnia w pindzel, pyrów sobie nastrugał, $\mathrm{w}$ domu by się został, tak, a nie na tory się jeszcze rechlać'), sztygać 'kuleć' („Niby sztygo, a jak przydzie co do czegu, to wszyńdzie piyrszy”), sztykutać 'kuśtykać' (,Jakiś dalas sztykuta z wysiłkiem, babina za nim też boleściwa”), terligać się 'ciężko, z trudem się poruszać' („Później, gdy już 
mogłem się samodzielnie poruszać, nie rozstawałem się $\mathrm{z}$ matką ani na chwilę. Terligałem się za nią wszędzie, gdzie trzeba i nie trzeba");

- i odwrotnie - sprawności fizycznej: być mobil 'być ruchliwym, żywym, rzutkim' („Dziadek, jak szedł na rente, był jeszcze całkiem mobil, no i wziął sobie stróżówkę w tartaku"), być na fleku 'być jeszcze sprawnym, być w pełni sił' („Ma osiemdziesione, a jeszcze dziadzia ciągle na fleku”), mieć gryf 'być zręcznym, mieć uzdolnienia, szczególnie manualne' („Rąbię też tej naszej astmatyczce drzewo, do czego mam wielki gryf, aż mnie podziwiają”), wypiglać się 'wydobrzeć, wyzdrowieć' („Tak gu ta choroba zmogła, ledwo sie z ni wypigloł");

- zmęczenia po wysiłku fizycznym: być bejt 'być wykończonym, skrajnie zmęczonym, osłabionym' (,Jak wracam z pracy jestem zawsze kompletnie bejt”), być do maku 'być do niczego' (,[...] to stary tryk, który już do maku jest”), być nie do mówienia 'nie mieć ochoty do rozmowy' („Łeb mi pęka. Nie jestem teraz z nikim do mówienia"), leżeć jak sznyta//sznytka 'leżeć bez ruchu, opadłszy z sił' („Na wyro świgom sie martwym bykiem, leże jak sznyta”), nachapać się 'napracować się' („No zarabiać zarabia, ale jak sie nachapie"), nagibać się 'naharować się, zmęczyć się przy pracy' („On to sie przy tym zbijaniu palet nagibie zdrowo"), narugać się 'nadźwigać się' („Ale sie narugałem na ty robocie!"), skataić się 'zmęczyć się' („Wuja wynosił do wylewu ze trzydzieści wymborków wody, skataił sie jak mysz, że ledwie dychał");

- spania: być na śpiku 'spać' („Myślała, że jes na śpiku, a ón spod oka szpycowol, jak mu w portfelu grzebie”), garować 'spać, drzemać' (,Z mojego nie mam pociechy. Przyjdzie z roboty i garuje do dziennika, naje się i potem znowu na tapczan”), iść // pójść nyny 'iść spać' („Pójdziesz nyny”), kalafa się komuś drze 'spać się komuś chce, ktoś ziewa' („Od rana mi się kalafa drze"), nynać 'spać' („Zmów paciorek, synuchna, i idź nynać”), pogarować 'pospać, podrzemać' (,Jak sobie po obiedzie ździebko pogaruje, to zaroz mo lepszy humór"), przegarować 'przespać” („Przegarowałym cały dzinnik i nie wiym, jako jutro pogoda"), robić nyny 'spać' (,My to robimy nyny jak dziecioki - już z kurami”), zażnq̨ć śpika 'twardo zasnąć' („Ale zażnął śpika!");

- spożywania pokarmów: dziochać ‘jeść głośno, łapczywie’ („Odkąd ma nową szczęke to dziocha tak, że nie można z nim jeść"), futrować 'jeść' (,Sznytki ze smolochem futrowali, że aż miło było patrzeć”), nabqbać się // nabómbać się 'opchać się, objeść się, opić się' („Niezdrowo sie tak nabąbać”), nabuchać się, nawtykać się, obuchać się 'najeść się, objeść się' („Tak 
sie nabuchałem, że pasek rozpinałem”, „Nawtykoł sie tych cukierków i teroz nie chce jeś kolacji”, „Tak sie obuchołym na imieninach u wuja Leóna, że oż mie potym kałóndek boloł"), odbeknq̨́ 'odbić się (komuś po jedzeniu)' („Dopiero jak po jedzeniu odbeknie, czuje, że naprawdę sobie podjadł”), przypominać się 'o spożytym jedzeniu: odbijać się' („Cały dzień przypominały mi sie dzisiaj te wczorajsze śledzie"), spucować//spucnać 'zjeść szybko, z apetytem' („Frącki nie było wew chacie, więc tylko spucłem ze trzy, śtery skibki zez gzikiem”), syrbać 'siorbać' (,Ady stary, nie syrb tak przy jedzyniu”), śrupać 'chrupać, głośno gryźć' („Mój to sobie lubiał śrupać galarepe, ale teroz już nie może, bo nie mo zębów"), udowić się 'udławić się' („Uwożej, nie udow sie - sóm ości”), wleciało, wpadło coś komuś w niemieckq dziurkę // do niemieckiej dziurki 'ktoś się zakrztusił' („Nie mów, jak jesz, bo ci chleb wpadnie do niemieckiej dziurki”), wmłócić 'zjeść łapczywie, dużo' („Frącka wmłóciła takom wuchte jedzy, że aż famuła gupio szpycowała”), wtetrać, ześrutować 'zjeść' („Chto wiync w te pyndy dó nos przydyrdo ten wtetro ślepe ryby z myrdyrdom", "Jak ón jes głodny, to byle co ześrutuje - byle ino dużo");

- czynności fizjologicznych związanych z wydalaniem: chorchlać 'pluć, spluwać hałaśliwie, bez zwracania uwagi na otoczenie' (,Co tak cióngle chorchlosz i chorchlosz, jakbyś chcioł płuca wypluć?”), jscać ‘siusiać' („Łe jery, ale mi sie chce jscać!"), mieć narżnięte, narżnq̨ć// nażnq̨ć 'wypróżnić się, oddać kał' („Na pół dnia go sadzam na nocniku, a i tak ma prawie zawsze w porach narżnięte", „Znowu łobuz jeden narżnął w gacie”), nasiurać 'nasiusiać' („Takie szportowne wyce opowiadoł, że dziewuchy w majty nasiurały ze śmiychu”), purtać - purtnqć 'puścić bąka, puścić wiatry' (,JJak sie nie wstydzisz tak głośno purtać!"), puszczać - puścić mare 'puszczać bąki, puścić bąka' („Wiara mglała w kościele: kadzidło, co chwile ktoś puszczoł mare. Nażarli sie po dugiym poście $\mathrm{i}$ tak $\mathrm{w}$ te piyrsze świynto Wielkanocy było"), ryknq̨ć 'puścić bąka' (,Cisza była i nagle słychać jak sobie ktoś ryknął”), siurać 'siusiać' („Zło jes, bo juchty wciónż ji w siyni siurajóm"), wiukać//wiukać się - wiuknq̨ć się 'po jedzeniu: odbijać się, odbić się' („Damy mu tej sodki jak chce, niech mu się wiuknie”), womitować 'wymiotować' („Co zjod, to womitowoł abo wiukoł");

- przemarznięcia: gurdzić się 'kulić się z zimna' („Co sie tak gurdzisz, zimno ci?"), skarkną́ 'przemarznąć' („Ubierz sie, bo skarkniesz jak nie wiym... mróz oż trzeszczy”), świrknąć 'marznąć' (,Zaczli my razym zrywać, a że od zimna pazury nom świrkły, to my musieli ciyngiym sie rozgrzewać u Edy w altanie, nie?"), zgurdzić się 'skulić się, skurczyć się 
z zimna' (,Zgurdził sie z zimna, dóndel mu z nosa wisioł, ale meczu nie opuścił");

- stanu upojenia alkoholowego: mieć brant 'mieć kaca' (,Jak tylko podniesłem się zez leżanki, aby tylko popiłem wody od ogórków (bo brant miałem jak diaski)"), mieć jednego siedzieć 'być pod wpływem alkoholu, być po jednym głębszym' (,Jo to zaroz poznóm, kiedy tyn mój brynkot mo jednygu siedzieć"), mieć wypite 'być pod wpływem alkoholu' (,Jak mam wypite, nie siadam za kierownicą"), sprawić sobie katanę 'upić się' („Spotkali się wieczorem, poszło parę połówek, sprawili sobie katanę i balowali do rana");

- cech fizycznych związanych z wiekiem: cacy, cacy - buch po glacy 'żartobliwa rymowanka odnosząca się do osoby łysej' („«Cacy, cacy - buch po glacy", myślałem sobie, oglądając w lustrze szarą, starzejącą się twarz z łysiejącym czołem"), jak na chlyb będziesz mówić byb, a na muchy ptapty 'wówczas, gdy będziesz już stary i niedołężny' (,Śmiej się, śmiej, zrozumiesz to, jak na chlyb będziesz mówić byb, a na muchy ptapty. Wtedy zobaczymy!"), mieć gzik pod nosem 'o kimś młodym, komu się wąs dopiero puszcza' (,Patrzcie go, gzik ma pod nosem, a już papieros w gębie, łapy w kieszeni i cie nie zna"), mieć pyszczek jak toruszke 'mieć bardzo pomarszczoną twarz' („A jo bez to schudne, że byde mioł niedugo szyjke jak mandolinke, a pyszczek jak toruszke!”), skapucieć 'zestarzeć się' („Patrz, pani, jak tyn Marych ostatnio skapucioł - widać, że już sie oglóndo na ksiynżóm obore");

- tuszy, sylwetki: kupa lumpów, a szczuna nie ma, same pory chodzq 'określenie chudej osoby' (,,[...] ale nie brenczcie, że głabłem szplina, że kupa lumpów, a szczuna ni ma!", "Zaraz potem przyknaił się konduktor - takie ramiączko, no, mówie wam - same pory chodzą, ale frechowny!");

- kobiety ciężarnej: być na ostatnich girach//giyrach//gierach 'być w zaawansowanej ciąży' (,Jak sie wojna zaczyła to jo na ostatnich giyrach byłam. Zyga sie urodził, to już Niymcy tu byli"), chodzić z korbolem 'być w ciąży', przechodzić 'przenosić ciążę' (,„...] mama już twierdziła, że albo nie wiem, kiedy sknociłam, albo przechodzę, co się nieraz zdarza");

- innych stanów i czynności: podany na kogoś, podobny na kogoś 'podobny do kogoś' („Z kalafy był leko podany na wuja Ignaca”, „Barzy podobny na matke jak na ojca”), wyciqgnqć szwaje 'umrzeć' („Jo wom wyciungne cheba szwaje, jak na tyn jarmark z nim poknaje").

Wyróżnione powyżej kręgi semantyczne czasowników i związków werbalnych dotyczących cech fizycznych człowieka pozwalają stwierdzić, 
że w polszczyźnie miejskiej Poznania, podobnie jak w ogólnopolskiej odmianie potocznej, zdecydowanie częściej nominacji podlegają czynności i stany wartościowane ujemnie (tu: słabość, niesprawność, ułomność, zmęczenie, obżarstwo itp.) oraz objęte językowym tabu (jak ciąża, wydalanie czy upojenie alkoholowe). W zasadzie jedyną niewielką klasę jednostek leksykalnych o pozytywnej ewaluacji stanowią nazwy odnoszące się do sprawności fizycznej (być mobil, być na fleku, mieć gryf, wypiglać się). Charakter neutralny mają zaś prawie wyłącznie określenia dotyczące snu. $\mathrm{Z}$ wartościowaniem tym wiąże się przynależność analizowanych leksemów do ekspresywnego rejestru poznańskich regionalizmów. W Słowniku gwary miejskiej Poznania opatrywanie haseł kwalifikatorami stylistyczno-ekspresywnymi nie zawsze jest konsekwentne. Przy wyekscerpowanych na potrzeby niniejszego artykułu jednostkach odnotowano jednak często jeden $\mathrm{z}$ dwu kwalifikatorów - ogólny ekspresywne, np.: rechlać się, ryknqú, siekło kogoś, ześrutować, lub szczegółowy żartobliwe, przykładowo: być do maku, mieć gzik pod nosem, przegarować, robić nyny, sprawić sobie katanę, spucować - spucnqćc. Nieliczne hasła opatrzone zostały w Słowniku dwoma kwalifikatorami, sygnalizującymi ich ambiwalentne zabarwienie, $\mathrm{np}$.: kwiendać (̇̇art., lekcew.), mieć w girach gzik (żart., iron.). Czasowniki i frazeologizmy określające czynności fizjologiczne związane $\mathrm{z}$ wydalaniem są najczęściej kwalifikowane jako wulgarne (np. mieć narżnięte, narżnq̨ć, puścić marę).

Struktura formalno-genetyczna analizowanych jednostek werbalnych dokładnie odzwierciedla strukturę poznańskiej leksyki regionalnej. Można tu wyróżnić następujące klasy leksemów:

- dialektyzmy zarówno wąskoterytorialne, np.: churchlać, dziochać, namóc, odbeknqú, przekarknq̨ć, rechlać się, skarknq̨ć, skataić się, śrupać, wiukać, wypiglać się, zgurdzić się, jak i szerokoterytorialne, np.: jscać, przebrać, przekopyrtnqć się, purtać - purtnqć, siurać, skalczyć się, świrknq̨́, terligać się, zatajać się - zataić się, ześrutować;

- germanizmy, takie jak: być na fleku (niem. auf dem Fleck sein), być nie do mówienia (niem. nicht zu sprechen sein), mieć jednego siedzieć (niem. einen sitzen haben), przekipnać się (niem. kippen), przypominać się (kalka niem. sich erinnern), sztygać (niem. steigen);

- archaizmy niegdyś obecne w polszczyźnie ogólnej, a dziś zachowane w odmianach regionalnych, przykładowo: skapucieć.

Zakresy owych klas częściowo zachodzą na siebie, bowiem wśród dialektyzmów spotkać można archaizmy (np. mgleć, nabuchać się, podany na ko- 
goś, udowić się, womitować, zagałuszyć się, zemglić) oraz germanizmy (np. futrować (niem. futtern), spucować - spucnać (niem. putzen)).

Różny jest też stopień stabilizacji przytaczanych tu regionalizmów. Nieliczne należą do powszechnych (przynajmniej takim kwalifikatorem zostały w Stowniku opatrzone) we wszystkich grupach pokoleniowych i warstwach społecznych poznaniaków ( $m a$ się komuś na zdech, mgleć, nachapać się, skarknać, womitować). Liczniejsze są wycofujące się lub wyszłe $\mathrm{z}$ użycia leksemy, sygnowane kwalifikatorami: wychodzqce z użycia (podany na kogoś, podobny na kogoś, skapucieć, skataić się, zgurdzić się), rzadkie (same pory chodzq, terligać się), przestarzałe (być mobil, być nie do mówienia, sztygać, umgleć), dawne (sztykutać). Pozostałe, nieopatrzone żadnym chronologicznym kwalifikatorem, regionalne czasowniki i frazeologizmy związane z czynnościami fizjologicznymi oraz stanem fizycznym człowieka należą zatem do względnie stabilnej, trwałej warstwy leksyki poznańskiej. Wraz z nazwami osób - zarówno ze względu na cechy fizyczne, jak i psychiczne - oraz z nazwami części ciała i nazwami zawodowymi omówiona wyżej kategoria semantyczna stanowi trzon antropocentrycznie zorientowanej leksyki regionalnej, nie tylko poznańskiej. Antropocentryzm ten w połączeniu $\mathrm{z}$ nacechowaniem ekspresywnym owego słownictwa jest główną przyczyną jego stabilności.

Wyrazy z gwary poznańskiej, które wystąpiły $\mathrm{w}$ artykule, a nie zostały objaśnione ${ }^{*}$

ady 'ale, ależ, przecież, no'

barzy//barzyj//barzej 'bardziej, więcej'

bez 'przez'

bręczeć//brynczeć powsz. 'marudzić, zrzędzić'

brękot//brynkot żart., lekc. 'maruda, zrzęda'

cheba 'chyba'

cięgiem// cingiem// cingim// ciyngiem// ciyngiym 'ciągle'

dalas 1. 'bieda, nędza, ciężkie czasy'; 2. rzad. 'biedak, nędzarz'

dundel// dóndel 1. 'wydzielina z nosa'; 2 . żart. 'malec, smarkacz'

dziadzia powsz. 'dziadek'

famuła 'rodzina'

frechowny 'bezczelny, zuchwały, arogancki'

\footnotetext{
* Formy hasłowe, kwalifikatory i definicje przytaczamy za Słownikiem gwary miejskiej Poznania.
} 
galarypa//galarepa 1. powsz. 'kalarepa'; 2. daw., uczn. 'galeria, miejsce w teatrze na najwyższym balkonie'

gilejza//gielejza//gelejza wyzw., pogardl. 'niezdara, osoba powolna, ślamazarna, niezręczna'

głabnąć szplina rzad., żart. 'dostać fioła'

gzik, rzadziej gzika 'twarożek, zwykle przyprawiony śmietaną i szczypiorkiem lub cebulą'

ino//jino//jyno 'tylko'

jedza przestarz. 'jedzenie'

juchta $w y z w$. 'chuligan, łobuz; przed I wojną światową i w okresie międzywojennym nazwa chuligana, przestępcy z Chwaliszewa, niedużej dzielnicy Poznania'

kalafa ekspr. 'twarz, gęba'

kałondek//kałóndek//kałundek//kałyndek 'żołądek'

leżanka powsz. 'rodzaj tapczanu; kozetka'

łe jery//(ł)o jery! powsz. 'o rany! o rety!'

majty 'majtki'

mój 'mąż'

nastrugać 'naobierać'

pazura ekspr. 'ręka'

poknaić 1. 'ponieść'; 2. 'pójssćc'

pory 'spodnie'

przehycnąć żart. 'przeskoczyć'

przydyrdać 'przyjść'

przyknaić się ekspr. 'przyjść, przywlec się'

pyra, rzadziej pera, częściej w $l m, D l m$-ów, powsz. 'ziemniak'

ramiączko//ramiąszko żart. 'określenie mężczyzny chudego, o wąskich ramionach'

ryczka powsz. 'niski taboret, stołeczek'

smoloch // smolóch 'smalec'

sodka//zodka wych. $z$ użycia 'woda z sodą (węglanem sodu) używana jako lekarstwo w kłopotach trawiennych'

synuchna 'synuś'

szczype 'trochę, szczyptę'

sznytka 'kromka chleba; kanapka'

szportowny 'śmieszny, wesoły, dowcipny'

szpycować - szpycnąć 'spoglądać, spojrzeć, zobaczyć'

ślepe ryby z// zez myrdyrdą//myrdyrdóm 'zupa ziemniaczana'

świgać się - śwignąć się 1. 'rzucać się, rzucić się'; 2. 'rzucić się (pójść, pobiec dokądś szybko)'; 3. 'stawiać się' 
wew 'w'

wiara powsz. 'grupa ludzi, tłum; także w ogóle: ludzie (często w wołaczu)'

wózik powsz. 'wózek'

wuchta 'wielka ilość, masa, mnóstwo, kupa'

wuja powsz. 1. 'wuj'; 2. ekspr. 'o mężczyźnie w ogóle'

wycyckać ekspr. 1. 'wyssać'; 2. 'wykorzystać, oszukać'

węborek//wemborek// wymborek 'wiadro'

wyc//witz//wic 'żart, dowcip, kawał'

zawdy 'zawsze'

zaś 1. 'w funkcji przysłówka: potem, później, następnie'; 2. 'w funkcji wzmocnienia ekspresji niektórych spójników i przysłówków'

zez//zes ' $z$ '

ździebko powsz. 'trochę'

\section{POZNAN REGIONAL VERBS AND IDIOMS CONNECTED WITH MAN'S PHYSIOLOGICAL FUNCTIONS AND PHYSICAL CONDITION}

\section{Summary}

The authors of the article present the analysis of about 100 Poznan regional lexical items that are verbal in nature and are connected with man's physiological functions and physical condition, and which are registered in Słownik gwary miejskiej Poznania [Poznan Urban Slang Dictionary] edited by Monika Gruchmanowa and Bogdan Walczak. The analysis of semantic categories represented by such verbs and idioms reveals that negatively evaluated functions and conditions (here: weakness, disability, handicap, tiredness, gluttony, etc.) as well as taboo words (such as pregnancy, excretion or intoxication) are much more frequently subject to designation. The above evaluation is combined with the fact that the analyzed lexemes belong to the expressive register of Poznan regionalisms. The anthropocentric character of the lexis quoted in the article and its emotional undertones influence a relatively stable status of these regionalisms in Poznan residents' spoken language. A formal structure of the lexis belonging to the above thematic group, i.e. the presence of archaisms, dialectisms and germanisms therein, reflects the origin of Poznan regional variety of the Polish language. 